\title{
Utilizing Donors with Hepatitis C Antibody Positivity and Negative Nucleic Acid Testing
}

\author{
Kimberly A. Brown ${ }^{1} \cdot$ Mona Hassan ${ }^{1}$
}

Published online: 25 October 2018

(C) Springer Nature Switzerland AG 2018

\begin{abstract}
Introduction The demand for organs in the USA exceeds supply resulting in high mortality for patients awaiting transplantation. To increase the pool of available organs, the transplant community is investigating the safety and utility of organs previously considered high risk. Guidelines currently advocate for the use of hepatitis $\mathrm{C}$ antibody, nucleic acid testing (NAT)-negative organs in hepatitis $\mathrm{C}-$ positive recipients. However, data is limited regarding outcomes of using such grafts in hepatitis $\mathrm{C}-$ negative recipients.

Purpose of Review The purpose of this paper is to review the literature on utilizing hepatitis C virus (HCV)-positive NATnegative livers and to determine if utilizing direct-acting antivirals lowers the risk of HCV transmission regardless of the recipient's HCV status.

Recent Findings The current literature demonstrates that the overall risk of transmission of HCV with the use of these organs in HCV-negative recipients is low and that risk is increased with high-risk donors that died from IVDA overdose.

Summary Direct-acting antivirals are highly effective in treating HCV and lowering the risk of transmission. Therefore, we should reconsider utilizing these organs in $\mathrm{HCV}$-positive recipients.
\end{abstract}

Keywords Liver transplantation - Extended criteria donors - Nucleic acid test · HCV antibody-positive/NAT-negative donors · $\mathrm{HCV}$ transplant transmission risk $\cdot$ Hepatitis $\mathrm{C}$-positive donors $\cdot$ Occult hepatitis $\mathrm{C}$

\section{Review Paper}

The mismatch of supply to demand for organs in the USA has pushed the transplant community to test various strategies geared toward increasing the organs available for transplantation. Hepatitis $\mathrm{C}$ antibody-positive organs have traditionally been considered high risk due to the concern of transmission of the virus from organ to recipient at the time of transplant. The hepatitis C virus was discovered in 1989. Routine testing of the US blood supply began in 1990 and with improved serologic testing becoming available in 1992, overall transmission of hepatitis $\mathrm{C}$ via blood supply was reduced significantly [1]. Nucleic acid testing (NAT) was implemented in 1999,

This article is part of the Topical Collection on Liver

Kimberly A. Brown

Kbrown1@hfhs.org

1 Division of Gastroenterology and Hepatology, Department of Medicine, Henry Ford Hospital, Detroit, MI, USA leading to further reduction in viral hepatitis $\mathrm{C}$ transmitted by blood transfusion [2,3]. The risk of transmission of infection via organ transplantation remained a concern due to the demonstration that transmission of HCV by a donor organ could lead to loss of the allograft and rarely recipient death. Data obtained from the UNOS database literature on cadaver kidney and heart transplantations that were performed from 1994 to 1997 demonstrated that $50 \%$ of $\mathrm{HCV}$-negative recipients of donor organs positive for IgG antibody to $\mathrm{HCV}$ formed detectable antibodies to $\mathrm{HCV}$ with detectable hepatitis $\mathrm{C}$ viremia by PCR analysis occurring in $24 \%$ and $35 \%$ developing liver disease [4]. The OR for recipients developing antibodies to $\mathrm{HCV}$ within 1 year of transplantation, in donors that tested positive for antibody to $\mathrm{HCV}$, was 12.94 in kidney transplant recipients and 31.83 in heart transplant recipients $[5,6]$.

In addition, previous reports suggested that recipients of HCV-positive organs had lower patient and graft survival as in comparison to recipients of $\mathrm{HCV}$-negative organs [7-9].

However, more recent data has demonstrated that both mortality and graft loss at 1,3 , and 5 years were not significantly different in the HCV-positive recipients of livers 
from HCV-positive or HCV-negative donors. Furthermore, in recipients of kidney transplants, the risk of receiving an HCV-positive kidney was minute leading to a $1 \%$ decreased survival at 1 year and a $2 \%$ decreased survival at 3 years [10-15].

There are currently guidelines provided by the Centers for Disease Control (CDC) to classify donors as high risk (increased risk of having an infectious disease). A donor is defined as "high risk" if they fall into any one or more of the following categories: men who have engaged in sex with men in the last 5 years, people that report non-medical intravenous, subcutaneous, or intramuscular drug use within the preceding 5 years, people with clotting disorders or hemophilia and have received human-derived clotting factors, men or women who have been involved in sexual activity for money or drugs in the 5 years preceding presentation, persons who have engaged in sexual intercourse in the last 12 months with any person listed above, people who have been exposed in the last 12 months to diagnosed or suspected HIV-infected blood and inmates or correctional systems [16].

The U.S. Public Health Service (PHS) published new guidelines in July 2013, in order to reduce hepatitis C virus (HCV) transmission through organ transplantation. These "increased risk" guidelines replaced guidelines from 1994. The term "increased risk" refers to donor features that could potentially place the recipient at increased risk of disease transmission [16].

The Organ Procurement and Transplantation Network/ United Network for Organ Sharing (OPTN/UNOS) ad hoc Disease Transmission Advisory Committee (DTAC), collaborated with the Joint Society Steering Committee to develop a document, which included recent peer reviewed literature and OPTN data, to define the risk of the transmission of undetected disease from increased risk DONORS [16]. The aim of this guidance document is to assist the transplant community in making decisions when organ offers are made from OPOs, allowing transplant physicians to evaluate the risk of undetected infection of the donor with HBV, HIV, or HCV. The document provides transplant program staff with information in order to provide patient education and gives guidance for the decision-making process for patients. Finally, the document aims to identify organ donors that were recently infected but appear negative on serologic testing and be capable of HIV, $\mathrm{HBV}$, or HCV transmission to recipients. The Organ Procurement and Transplantation Network/United Network for Organ Sharing (OPTN/UNOS) policy has mandated informed consent being obtained from recipients that receive organs from increased risk donors and post-transplant follow-up for all recipients of organs from increased risk donors is recommended [17].

HCV nucleic acid testing (NAT) is now recommended by the PHS guidelines prior to organ procurement when screening all deceased donors [18]. This recommendation is intended to decrease transmission risk since NAT decreases the risk of serologic non-detection of $\mathrm{HCV}$ at the time of the window period by about tenfold in most cases [19]. The impact of HCV antibody status and NAT on donor utilization is undetermined and only recently has NAT testing become routine, as all organ procurement organizations were mandated in 2015 to report and perform NAT testing on all donors whether they are deceased or living [20].

Since the application of these new policies, the number of possible increased risk deceased donors has gone up nationally to approximately one in five donors [21]. There are currently rising rates of donors that are HCV antibody-positive and NAT-negative due to the increasing rates of intravenous drug use and advances in HCV therapy. According to the CDC data, opioid overdose deaths were five times higher in 2016 than in 1999 and opioids were involved in 42,249 deaths in 2016 [22]. In fact, there was a recent abrupt surge in opioid use in the USA, which resulted in a significant rise in transmission of HCV, injection drug use, and deaths from opioid overdose. There has also been a rapid increase in recovery and utilization of HCV-positive donor organs in areas most affected by the opioid epidemic. The proportion of hepatitis $\mathrm{C}$-positive deceased donor LTs in the USA has increased nearly twofold in the last 3 years [23].

Data has shown that organs from donors defined as increased risk are less likely to be utilized and more likely to be discarded compared to organs from donors that are not increased risk $[24,25]$. This is surprising considering the fact that post-transplant patient and graft survival with high-risk organs is better or equal to that of non-increased risk organs [26]. Data demonstrates that the percentage of organ procurements from donors defined as increased risk donors increased from 12.3 to $19.5 \%$ and superseded $25 \%$ in 2015 in 14 organ procurement organizations [26]. However, data from the OPTN demonstrates that despite the rise in increased risk organ donors during the period 2010 to 2015 , not all centers utilize these organs. Between 2010 and 2015, only 16.4 to $42.3 \%$ of transplant programs performed transplants using high-risk donor organs in at least $10 \%$ of their recipients. In fact, from 2005 to 2014, increased risk donors were not utilized in as many as $16.4 \%$ of transplant programs, depending on the organ type [27]. Data also showed that the level of risk is not equal among all high-risk organ donors [26]. So, although these organs are increasingly available for transplantation, many centers remain reluctant to use them for their recipients.

Organs from individuals that are HCV antibody-positive/ NAT-negative have generally not been utilized for donation to $\mathrm{HCV}$-negative recipients and have been reserved for patients with positive HCV RNA due to the scant amount of data on the $\mathrm{HCV}$ transmission risk from these organs to non-infected recipients. However, with widespread use of NAT testing, utilization of HCV antibody-positive, NAT-negative organs 
is being reconsidered. The recent American Society of Transplantation guidelines emphasize the importance of distinguishing HCV-positive/NAT-positive donors from NAT-negative HCV-positive donors [28]. The risk of increased risk donors with negative serologic screening transmitting HCV infection has been estimated to be from 300.6 in IVDA and 0.26 in hemophiliacs per 10,000 donors and 0.26 in hemophiliacs [27]. Therefore, the OPTN policy requires all increased risk donors undergo NAT testing (for HIV and HCV). However, HCV can be transmitted to organ recipients even when donors have a negative NAT [23]. In increased risk donors with increased risk behaviors for the acquisition of $\mathrm{HCV}$ infection, especially injection drug use, this likely reflects the "eclipse phase." The definition of the eclipse phase "previremic phase" is the time between virus exposure and when the virus can be detected in the plasma (new virion production) [29].

Overall, previous studies have suggested a $0.32 \%$ risk of $\mathrm{HCV}$ transmission from high-risk individuals that were NATnegative and HCV antibody-positive [30]. However, the Disease Transmission Advisory Committee of Organ Procurement and Transplantation Network estimates HCV transmission risk from donors with immediate needle exposure to be approximately $3 \%$. [19]

Current available literature demonstrates that NAT-negative/HCV antibody-positive serology can occur due to four mechanisms: previous exposure and successful treatment of $\mathrm{HCV}$, spontaneous clearance of $\mathrm{HCV}$ at the time of infection, an HCV antibody test that is falsely positive, or a HCV RNA that is falsely negative $[31-34,35 \cdot, 36]$. In an analysis of 66 studies by Cooke et al., the risk of reinfection or late relapse post-sustained virologic response (SVR) was $0.9 \%$ at 5 years in low-risk patients, $21.8 \%$ in $\mathrm{HIV} / \mathrm{HCV}$ co-infected patients, and $8.1 \%$ in HCV monoinfected IV drug users or prisoners [37, 38]. These individuals who have achieved SVR would remain HCV antibody-positive but NAT-negative. Furthermore, based on the literature, there is no evidence to support hepatitis $\mathrm{C}$ reactivation in the immunosuppressed host. [39].

Spontaneous clearance may occur following infection as well. In a cohort study by Tyndall et al., the spontaneous $\mathrm{HCV}$ clearance was observed to be $23.5 \%$ in 762 individuals between 1999 and 2005 that were HCV antibody- and RNApositive. Persistence of HCV was demonstrated in 583 individuals $(76.5 \%)$. The study also demonstrated that the spontaneous clearance rate of $\mathrm{HCV}$ was decreased in subjects that used any illicit drugs no matter the type of illicit agent [40].

The percentage of falsely positive hepatitis $\mathrm{C}$ antibody results was approximately $35 \%$ (range 15 to $60 \%$ ) in immunocompetent individuals and $15 \%$ in immunocompromised populations. The explanation for false-positive anti-HCV results is the fact that no structural proteins and antigens have been obtained from HCV up to now. There is a strong tendency for some of the $\operatorname{IgG}$ molecules to be bound to the micro-well surface by indirect capture via the surface molecules, or by direct adsorption and then create a signal, providing falsepositive results because of the high IgG concentration in human blood (>5 mg/mL) [41-43].

Finally, HCV RNA may be falsely negative. The titer of HCV RNA will decline as the titer of anti-HCV increases during acute infection [44] Therefore, HCV RNA is not identified in certain people during the acute phase of their hepatitis $\mathrm{C}$; however, this finding can be transient.

HCV RNA can be identified in blood 1 to 2 weeks post infection in most patients. HCV likely establishes infection in susceptible hepatocytes during the eclipse phase. Therefore, the use of qualitative HCV RNA assays with very high sensitivity will occasionally detect HCV RNA in the blood at levels less than 10 copies $/ \mathrm{mL}$ in blood. After the eclipse phase, there is an 8- to 10-day "ramp-up" phase. HCV replication increases exponentially during this phase and can be detected in plasma. At 6 to 10 weeks after infection, HCV RNA levels typically peak and this is known as the plateau phase. HCV RNA detection during acute infection is not completely reliable as HCV RNA levels can fluctuate and in some cases, HCV RNA levels are undetectable. However, HCV RNA levels are present with the onset of symptoms [45]. Current HCV NAT testing has a sensitivity value of $99 \%$ and specificity values of 98 to $99 \%$; therefore, qualitative PCR has been replaced by quantitative PCR. [41]

The relative risk of transmission of HCV from liver grafts of HCV NAT-negative donors remains unknown [46, 47]. Data from Suryaprasad et al. reported newly detected donorderived $\mathrm{HCV}$ after transplantation in organ recipients from increased risk donors. Cases were defined as recipients of solid organs with either undetectable HCV NAT or nonreactive anti-HCV antibody in the 6 months prior to transplant that were found to have detectable HCV RNA within 12 weeks of transplantation. HCV RNA was detected retrospectively in donor tissue collected at organ procurement in stored lymphocyte or splenocyte samples. Cases were confirmed as donorderived when other possibilities for HCV infection were excluded and after exclusion, HCV HVR-1 sequences from two or more recipients were genetically related to each other through molecular analyses or when HCV RNA was detected from stored serum obtained from the organ donor in the week preceding death or in the archived lymphocyte or splenocyte specimen obtained at organ recovery from the donor. All donors were NAT-negative and there was evidence of injection drug use preceding each donor's death. Of the 12 recipients, 8 were found to be $\mathrm{HCV}$-infected and 6 were newly diagnosed after transplant. This data identified the first known transmissions of HCV from NAT-negative increased risk organ donors, demonstrating significantly recent donor infection [48••].

Bari et al. recently performed a prospective study that demonstrated an HCV transmission rate of $16 \%$ (with a mean follow-up period of 11 months) in $25 \mathrm{HCV}$-negative 
recipients of $\mathrm{HCV}$ antibody-positive NAT-negative organs. The average age of this patient population was 62 years (range 36-69) and the median meld was 22. Eighty-eight percent of donors were Caucasian and $60 \%$ died of presumed of drug overdose. None of the recipients had behavior risk factors for $\mathrm{HCV}$ infection and did not have any other healthcare exposure that could have served as a source for infection. Two patients who received simultaneous liver and kidney transplants and one patient who received two liver transplants were included. This is the first prospective study to assess $\mathrm{HCV}$ transmission from such donors. Four patients acquired $\mathrm{HCV}$ infection post-transplant and three were treated with direct-acting antiviral therapy with two achieving a sustained virologic response and the third patient having an end-of-treatment response. Although this study was not powered to draw conclusions on other factors that may increase transmission risk, it does provide some idea regarding transmission risk. One hundred percent of the HCV transmission occurred from donors that died from drug overdose. This may have relevance in the selection of donors given that high-risk donors dying secondary to drug overdose may be more likely to have negative NAT testing if recent infection has occurred [49••]. The overall risk of transmission in this situation appears to be low with $\mathrm{HCV}$ antibody-positive/NAT-negative donor organs. Given the better organ quality and younger age of some of these donors, it seems relevant to consider utilizing these organs. Nevertheless, it is vital that liver transplant recipients understand the potential for transmission despite negative NAT and the limitations of currently available testing.

Another proposed mechanism of transmission is occult hepatitis $\mathrm{C}$ infection being present in the donor tissue. The definition of occult hepatitis $\mathrm{C}(\mathrm{HCV})$ is the presence of the $\mathrm{HCV}$ genome in either peripheral blood monocytes or liver tissue, despite constant negative results from tests for $\mathrm{HCV}$ RNA in serum. Occult hepatitis $\mathrm{C}$ has been identified in patients with spontaneous or treatment-induced recovery from hepatitis $\mathrm{C}$ and with abnormal results of liver function tests of unknown origin, in anti-HCV-positive individuals with normal liver enzymes, and in subjects at risk for $\mathrm{HCV}$ infection such as hemodialysis patients or family members of patients with occult HCV. Occult HCV infection has also been detected in healthy people with no evidence of liver disease. A prospective study was performed by Elmasry et al. on 134 patients with recurrent $\mathrm{HCV}$ infection, based on HCV RNA testing, who were treated with direct-acting antivirals (DAAs) after liver transplantation, with or without ribavirin, from 2014 through 2016. Data revealed that 129 patients achieved an SVR12 and that in $>10 \%$ of the patients who achieved SVR12 $(n=14)$, serum levels of aminotransferases did not normalize during or after DAA therapy, or they normalized transiently but then increased sharply after DAA therapy. Of these 14 patients, 9 were assessed for occult HCV infection by reverse transcription quantitative polymerase chain reaction. This analysis revealed that $55 \%$ of these patients had an occult infection, indicating viral replication. These findings demonstrate that occult $\mathrm{HCV}$ infection can be present in some patients with abnormal levels of serum aminotransferases, despite SVR12 to DAAs for HCV infection after liver transplantation. [34, 35•] This may have potential implications for donor organs from previously treated patients in that these donors would likely test positive for HCV antibody and have negative NAT.

We recognize that infection of the graft in patients with untreated hepatitis $\mathrm{C}$ infection that receive liver transplantation occurs nearly universally. Reinfection has been demonstrated to occur as soon as reperfusion of the allograft has occurred. In these cases, viral levels have been found to reach pre-transplantation titers within $72 \mathrm{~h}$ of transplantation. In patients with $\mathrm{HCV}$ reinfection/infection post-liver transplantation, $20 \%$ have normal or near normal aminotransferase values with minimal inflammation on liver biopsy, less than $10 \%$ develop severe fibrosing cholestatic hepatitis, and the rest can develop chronic hepatitis [50, 51]. HCV-related fibrosis progression after liver transplantation has an accelerated course when compared with this condition pre-transplant. This resulted in outcomes which were inferior for HCVpositive recipients as compared to recipients who were HCV-negative.

However, there are currently multiple direct-acting antiviral agents for the treatment of hepatitis $\mathrm{C}$ post-transplantation as depicted in the AASLD IDSA HCV guidance (https:// www.hcvguidelines.org).

Treatment of HCV-positive patients was previously limited by the low success rates and side effects of older regimens. The advent of highly efficacious, new treatments for HCV has made clearance of HCV with excellent tolerance and efficacy possible. New direct-acting antivirals have allowed treatment in both decompensated as well as post-transplant recipients. In fact, the overall treatment response (cure) approaches that of pre-transplant patients if treated soon after transplantation [52].

Given the excellent efficacy and tolerance of new antiviral treatments for $\mathrm{HCV}$, the opportunity of using $\mathrm{HCV}$-positive donors for HCV-negative recipients has been explored by the transplant community. Desai et al. performed a single-center open-label nonrandomized trial to determine the tolerability and feasibility of using direct-acting antivirals (DAAs) as prophylaxis before and after kidney transplantation from $\mathrm{HCV}$ infected donors to non-HCV-infected recipients (HCV D+/Rtransplantation). The study population included $10 \mathrm{HCV} \mathrm{D+/}$ $\mathrm{R}$ - kidney transplant candidates older than 50 years with no available living donors. All recipients received a dose of grazoprevir (GZR), $100 \mathrm{mg}$, and elbasvir (EBR), $50 \mathrm{mg}$, immediately before transplantation. Recipients of kidneys from donors with genotype 1 infection continued receiving GZR- 
EBR for 12 weeks after transplantation; those receiving organs from donors with genotype 2 or 3 infection had sofosbuvir, $400 \mathrm{mg}$, added to GZR-EBR for 12 weeks of triple therapy. Results demonstrated that pre- and posttransplantation $\mathrm{HCV}$ treatment was safe and prevented chronic $\mathrm{HCV}$ infection in $\mathrm{HCV} \mathrm{D}+\mathrm{R}-$ kidney transplant recipients [53]. If this can be confirmed in larger studies, this should markedly expand organ options and decrease mortality in transplant candidates that do not have HCV infection. Furthermore, the use of pan-genotypic regimens should obviate the need for HCV genotyping at the time of or after transplantation [54].

However, we must remain aware that there are factors that may potentially impact our ability to achieve a cure in the setting of donor-related transmission and we need to be mindful that the cost of medications can be prohibitive for patients requiring insurance approval. Insurance companies often restrict the use of these medications and may not cover the medication most appropriate for the patient depending on the HCV genotype and prior recipient or donor medication exposure. In addition, many insurance companies require patients to demonstrate significant liver fibrosis prior to approval, which would prevent any attempt at "preemptive" treatment. Finally, approval of therapy may take weeks, which may influence patient ability to respond, especially in cases of fibrosing cholestatic recurrence [55].

In summary, there are an increasing number of increased risk donors positive for hepatitis $\mathrm{C}$. Although transmission of $\mathrm{HCV}$ is possible despite negative NAT testing in an organ which is $\mathrm{HCV}$ antibody positive, the risk remains low. Ideally, we should utilize these organs in HCVpositive recipients. However, due to the low risk of $\mathrm{HCV}$ infection transmission and the availability of highly efficacious treatment for $\mathrm{HCV}$, it is likely that the benefit of receiving an organ outweighs the potential risk of graft loss or death from NAT-negative HCV antibody-positive organs. It is important to make sure that recipients understand the limitations of the currently available testing strategies and that there is the potential for transmission despite HCV NAT testing being negative. The creation of protocols for monitoring and reporting of newly detected infections and early post-transplant HCV RNA screening of recipients are critical to detecting patients with new infections that may benefit from antiviral regimens.

\section{Compliance with Ethical Standards}

Conflict of Interest The authors declare that they have no conflict of interest.

Human and Animal Rights and Informed Consent This article does not contain any studies with human or animal subjects performed by any of the authors.

\section{References}

Papers of particular interest, published recently, have been highlighted as:

- Of importance

- Of major importance

1. Szabo E, Lotz G, Paska C, Kiss A, Schaff Z. Viral hepatitis: new data on hepatitis C infection. Pathol Oncol Res: POR. 2003;9(4): 215-21.

2. World Health Assembly, 63: Viral hepatitis - report by the secretariat 2010. http://apps.who.int/iris/handle/10665/2383. (last accessed April 19, 2017).

3. Roth WK, Busch MP, Schuller A, Ismay S, Cheng A, Seed CR, et al. International survey on NAT testing of blood donations: expanding implementation and yield from 1999 to 2009. Vox Sang. 2012;102:82-90.

4. Pereira B. Levey A. Hepatitis $\mathrm{C}$ virus infection in dialysis and renal transplantation. Kidney Int. 1997;51:981-99.

5. Fishman J, Rubin R, Koziel M, Periera B. Hepatitis C virus and organ transplantation. Transplantation. 1996;62:147-54.

6. David R. Snydman, Section Editor. Special section: infections in transplantation and other immunocompromised hosts cadaver donor screening for infectious agents in solid organ transplantation Francis L. Delmonico New England Organ Bank and Harvard Medical School, Newton, Massachusetts.

7. Ballarin R, Cucchetti A, Spaggiari M, Montalti R, Di Benedetto F, Nadalin S, et al. Long-term follow up and outcome of liver transplantation from anti-hepatitis $\mathrm{C}$ virus-positive donors: a European multicentric case-control study. Transplantation. 2011;91:1265-72.

8. Lai JC, O'Leary JG, Trotter JF, Verna EC, Brown RS Jr, Stravitz RT, et al. For Consortium to Study Health Outcomes in HCV Liver Transplant Recipients (CRUSH-C). risk of advanced fibrosis with grafts from hepatitis $\mathrm{C}$ antibody-positive donors: a multi-center cohort study. Liver Transpl. 2012;18:532-8.

9. Kucirka LM, Peters TG, Segev DL. Impact of donor hepatitis C virus infection status on death and need for liver transplant in hepatitis $\mathrm{C}$ virus-positive kidney transplant recipients. Am J Kidney Dis. 2012;60:112-20.

10. Kucirka LM, Peters TG, Segev DL. Impact of donor hepatitis C virus infection status on death and need for liver transplant in hepatitis $\mathrm{C}$ virus-positive kidney transplant recipients. Am J Kidney Dis. 2012;60:112-20.

11. Stepanova M, Sayiner M, de Avila L, Younossi Z, Racila A, Younossi ZM. Long-term outcomes of liver transplantation in patients with hepatitis $\mathrm{C}$ infection are not affected by HCV positivity of a donor. BMC Gastroenterol. 2016;16:137.

12. Reese PP, Abt PL, Blumberg EA, Goldberg DS. Transplanting hepatitis C-positive kidneys. N Engl J Med. 2015;373:30-305.

13. Israni AK, Zaun D, Bolch C, Rosendale JD, Schaffhausen C, Snyder JJ, et al. OPTN/SRTR 2015 annual data report: deceased organ donation. Am J Transplant. 2017;17(suppl 1):503-42.

14. Mehra MR, Canter CE, Hannan MM, Semigran MJ, Uber PA, Baran DA, et al. The 2016 International Society for Heart Lung Transplantation listing criteria for heart transplantation: a 10- year update. J Hear Lung Transplant. 2016;35:1-23.

15. Velidedeoglu E, Desai NM, Campos L, Olthoff KM, Shaked A, Nunes F, et al. The outcome of liver grafts procured from hepatitis C-positive donors. Transplantation. 2002;73:582-7.

16. Seem DL, Lee I, Umscheid CA, Kuehnert MJ. PHS Guideline for reducing Human Immunodeficiency Virus, Hepatitis B virus, and Hepatitis $\mathrm{C}$ virus transmission through organ transplantation. Public Health Reports. 2013;128(4):247-343. 
17. Gordon EJ, Mullee J, Beauvais N, Warren E, Theodoropoulos N, $\mathrm{McNatt} \mathrm{G}$, et al. Education and informed consent about increased risk donor kidneys: a national survey of non-physician transplant providers. Transpl Infect Dis. 2014;16(2):251-60.

18. OPTN Policy 2.9 Required deceased donor infectious disease testing, https://optn.transplant.hrsa.gov/media/1200/optn_policies. pdf\#nameddest=Policy_02

19. Kucirka LM, Sarathy H, Govindan P, Wolf JH, Ellison TA, Hart LJ, et al. Risk of window period hepatitis-C infection in high infectious risk donors: systematic review and meta-analysis. Am J Transplant. 2011;11(6):1188-200.

20. Kling CE, Limaye AP, Sibulesky L. Changing landscape of hepatitis C virus-positive donors. World J Hepatol. 2017;9(20):905-6.

21. Kucirka LM, Bowring MG, Massie AB, Luo X, Nicholas LH, Segev DL. Landscape of deceased donors labeled increased risk for disease transmission under new guidelines. Am J Transplant. 2015;15(12):3215-23.

22. Hedegaard H, Warner M, Miniño AM. Drug overdose deaths in the United States, 1999-2016. NCHS Data Brief, no 294. Hyattsville, MD: National Center for Health Statistics. 2017/CDC. Wideranging online data for epidemiologic research (WONDER). Atlanta, GA: CDC, National Center for Health Statistics; 2016. Available at http://wonder.cdc.gov

23. Gonzalez SA, Trotter JF. The rise of the opioid epidemic and hepatitis $C$ positive organs: A new era in liver transplantation. Hepatology. 2017;67(4):1600-1608.

24. Duan KI, Englesbe MJ, Volk ML. Centers for disease control 'highrisk' donors and kidney utilization. Am J Transplant. 2010;10(2): 416-20.

25. Volk, ML, Wilk, A, Wolfe, C, Kaul, DR, The 'PHS increased risk' label is associated with non-utilization of hundreds of organs per year, (presentation, American Transplant Congress. Boston, MA, 2016).

26. Understanding the risk of transmission of HIV, hepatitis B, and hepatitis C from U.S. PHS Increased Risk Donors. Guidance document. Optn.transplant.hrsa.gov.

27. Kucirka LM, Sarathy H, Govindan P, Wolf JH, Ellison TA, Hart LJ, et al. Risk of window period HIV infection in high infectious risk donors: systematic review and meta-analysis. Am J Transplant. 2011;11(6):1176-87.

28. Ison, MG, Risky business: does all risky behavior increase risk equally, Presentation, American Transplant Congress, Philadelphia, PA, May 5, 2015.

29. Kakizoe Y, Nakaoka S, Catherine A, Beauchemin A, Morita S, Mori $\mathrm{H}$, et al. A method to determine the duration of the eclipse phase for in vitro infection with a highly pathogenic SHIV strain. Sci Rep. 2015;5:10371.

30. Villano SA, Vlahov D, Nelson KE, Cohn S, Thomas DL. Persistence of viremia and the importance of long-term follow-up after acute hepatitis C infection. Hepatology. 1999;29(3):908-14.

31. Cox AL, Netski DM, Mosbruger T, Sherman SG, Strathdee S, Ompad D, et al. Prospective evaluation of community-acquired acute-phase hepatitis C virus infection. Clin Ifect Dis. 2005;40(7): 951-8.

32. Castillo I, Rodriguez-Inigo E, Lopez-Alcorocho JM, Pardo M, Bartolome J, Carreno V. Hepatitis C virus replicates in the liver of patients who have a sustained response to antiviral treatment. Clin Infect Dis. 2006;43(10):1277-83.

33. McHutchinson JG, Poynard T, Esteban-Mur R, Davis GL, Goodman ZD, Harvey J, et al. Hepatic HCV RNA before and after treatment with interferon alone or combined with ribavirin. Hepatology. 2002;35(3):688-93.

34. Whitcomb E, Choi WT, Jerome KR, Cook L, Landis C, Ahn J, Te HS, et al. Biopsies from allograft liver contain histologic features of hepatitis $\mathrm{C}$ virus infection following virus eradication. Clin Gastroenterol Hepatol. 2017;15(8):1279-85.
35. Elmasry S, Wadhwa S, Bang BR, Cook L, Chopra S, Kanel G, et al. Detection of occult hepatitis $\mathrm{C}$ infection in patients who achieved a sustained virologic response to direct-actingantiviral agents for recurrent infection after liver transplantation. Gatroenterology. 2017:152(3):550-553.e8 This is an important study as it is a prospective study demonstrating the presence of occult $\mathrm{HCV}$ infection in some patients with abnormal levels of serum aminotransferases, despite SVR12 to DAAs after liver transplantation.

36. Grebely J, Raffa JD, Lai C, Krajden M, Conway B, Tyndall MW. Factors associated with spontaneous clearance of hepatitis $\mathrm{C}$ virus among illicit drug users. Can J Gastroenterol. 2007;21(7):447-51.

37. Cooke GS, Lemoine M, Thursz M, Gore C, Swan T, Kamarulzaman A, et al. Viral hepatitis and the global burden of disease: a need to regroup. J Viral Hepat. 2013;20:600-1.

38. Andrew Hill, Bryony Simmons, Jawaad Saleem, Graham Cooke. Risk of late relapse or re-infection with hepatitis $\mathrm{C}$ after virologic response: metanalysis of 66 studies. Conference on Retroviruses and Opportunistic Infections 2015.

39. Einav $S$, Koziel MJ. Immunopathogenesis of hepatitis $C$ virus in the immunosuppressed host. Transpl Infect Dis. 2002;4(2):85-92.

40. Grebely J, Raffa JD, Lai C, Krajden M, Conway B, Tyndall MW. Factors associated with spontaneous clearance of hepatitis $\mathrm{C}$ virus among illicit drug users. Can J Gastroenterol. 2007;21(7):447-51.

41. Gupta E, Bajpai M, Choudhary A. Hepatitis C virus: screening, diagnosis, and interpretation of laboratory assays. Asian J Transfus Sci. 2014;8(1):19-25.

42. Moorman AC, Drobenuic J, Kamili S. Prevalence of false-positive hepatitis $\mathrm{C}$ antibody results, national health and nutrition examination study (NHANES) 2007-2012. J Clin Virol. 2017;89:1-4. https://doi.org/10.1016/j.jcv.2017.01.007.

43. Toyoda H, Kumada T, Kiriyama S, Sone Y, Tanikawa M, Hisanaga $\mathrm{Y}$, et al. Changes in hepatitis $\mathrm{C}$ virus (HCV) antibody status in patients with chronic hepatitis $\mathrm{C}$ after eradication of hcv infection by interferon therapy. Clin Infect Dis. 2005;40(6):e49-54.

44. Yusuke Kakizoe, Shinji Nakaoka, Catherine A. A. Beauchemin, Satoru Morita, Hiromi Mori, Tatsuhiko Igarashi, Kazuyuki Aihara, Tomoyuki Miura, and Shingo Iwami. A method to determine the duration of the eclipse phase for in vitro infection with a highly pathogenic SHIV.

45. Hajarizadeh, B, Grady B, Page K, Kim AY, McGovern BH, Cox $\mathrm{AL}$, Rice TM, et al. Factors associated with hepatitis $\mathrm{C}$ virus RNA levels in early chronic infection: the InC3 Study. J Viral Hep. 2015;22(9):708-17.

46. Organ procurement and transplantation network. National Data.https://optn.transplant.hrsa.goc/data/view-data-reports/ national-data/\#. Accessed 2017.

47. Levitsky J, Formica RN, Bloom RD, Charlton M, Curry M, Friedwald J, Friedman J et al. The American Society of Transplantation Consensus Conference on the use of hepatitis C viremic donors in solid organ transplantation. Am J Transplant 2017;17(11): 2790-2802.

48.• Suryaprasad A, Basavaraju SV, Hocevar SN, Theodoropoulos N, Zuckerman RA, Hayden T, et al. Transmission of hepatitis C virus from organ donors despite nucleic acid test screening. Am J Transplant. 2015;15:1827-35 This study is relevant as it is the first study reporting newly detected donor-derived HCV after transplantation in organ recipients from increased risk donors.

49.• Bari K, Luckett K, Kaiser T, Diwan T, Cuffy M, Schoech M, et al. Hepatitis C transmission from seropositive, non-viremic donors to non-hepatitis C liver transplant recipients. Hepatology. 2017. https://doi.org/10.1002/hep.29704 This study is important as it the first prospective study looking at $\mathrm{HCV}$ transmission in $\mathrm{HCV}$-negative recipients of $\mathrm{HCV}$ antibody-positive NAT-negative organs. 
50. Grassi A, Ballardini G. Post-liver transplant hepatitis $\mathrm{C}$ virus recurrence: an unresolved thorny problem. World J Gastroenterol. 2014;20(32):11095-115.

51. Hori T, Onishi Y, Kamei H, Kurata N, Ishigami M, Ishizu Y, et al. Fibrosing cholestatic hepatitis $\mathrm{C}$ in post-transplant adult recipients of liver transplantation. Ann Gastroenterol. 2016;29(4):454-9.

52. Kwo PY. Direct acting antiviral therapy after liver transplantation. Curr Opin Gastroenterol. 2016;32:152-8.
53. Durand CM, Bowring MG, Brown DM, Chattergoon MA, Massaccesi G, Bair N, et al. Direct-acting antiviral prophylaxis in kidney transplantation from hepatitis $\mathrm{C}$ virus-infected donors to noninfected recipients: an open-label nonrandomized trial. Ann Intern Med. 2018;168:533-40. https://doi.org/10.7326/M17-2871.

54. Chute DF, Chung RT, Sise ME. Direct-acting antiviral therapy for hepatitis $\mathrm{C}$ virus infection in the kidney transplant recipient. Kidney Int. 2018;93(3):560-7.

55. Brown K. Maximizing donors with viral hepatitis in the current era. Liver Transplant 2017;23(S1): S44-49. 